\title{
COUNTERPRODUCTIVE WORK BEHAVIOURS: CLARIFY THE ROLE OF JOB DISSATISFACTION AND ORGANIZATIONAL INJUSTICE AS ATTITUDINAL PREDICTORS
}

\author{
Beatrice Piccoli, University of Verona, Verona, Italy
}

dx.doi.org/10.18374/IJBR-13-4.7

\begin{abstract}
Counterproductive work behaviours (CWB) are discretionary behaviours that violate organizational rules thus endangering the well-being of the organization and its members. Workplace deviance is a pervasive and expansive problem for the organizations and, consequently, it has become increasingly important to managers and organizational scholars. This study intends to clarify the roles of job dissatisfaction and organizational injustice perceptions in predicting counterproductive work behaviours. Drawing on theoretical bases, the author compared three possible models using structural equation modelling: full mediation (job dissatisfaction mediates injustice-CWB relationship), partial mediation (direct and indirect relationship through job dissatisfaction - between injustice and CWB) and independent effects model (job dissatisfaction and injustice are separate predictors of CWB). The results show greatest support for the second model where job dissatisfaction is a partial mediator of injustice-CWB relationship. The article considers in particular the implications of the results for research and managerial practices and proposes suggestions for theory development.
\end{abstract}

Keywords: Counterproductive Work Behaviours; Job Dissatisfaction; Organizational Injustice Perceptions; Structural Equation Modelling, Model Comparison Research. 